\title{
Characterization of the motor performance of newborns in a neonatal unit of tertiary level
}

\author{
Vera LÚCIa Jornada KreBs ${ }^{4 *}$ \\ 'Physiotherapist, Instituto da Criança, Hospital das Clínicas, Faculdade de Medicina, Universidade de São Paulo (HC-FMUSP), São Paulo, SP, Brazil \\ ${ }^{2}$ Director of the Physiotherapy Service, Instituto da Criança, HC-FMUSP, São Paulo, SP, Brazil \\ ${ }^{3}$ Full Professor of Intensive Care/Neonatology, Department of Pediatrics, FMUSP, São Paulo, SP, Brazil \\ ${ }^{4}$ Habilitation (BR: Livre-docência) - Head Physician of the Neonatal Center, Instituto da Criança, HC-FMUSP, São Paulo, SP, Brazi
}

luciana Giachetta ${ }^{1}$, Carla Marques Nicolau ${ }^{1}$, Regina Célia Turola Passos Juliani², Werther Brunow de Carvalho³,

Study conducted at Centro Neonatal do Instituto da Criança, Hospital das Clínicas, Faculdade de Medicina, Universidade de São Paulo (HC-FMUSP),São Paulo, SP, Brazil

Article received: 6/29/2016 Accepted for publication: $7 / 26 / 2016$

*Correspondence: Instituto da Criança Address: Av. Dr. Enéas de Carvalho Aguiar, 647

São Paulo, SP - Brazil Postal code: 05403-901 vera.krebs@hc.fm.usp.br

\section{SUMmARY}

Objective: To characterize the motor performance of newborns in a neonatal unit of tertiary level and compare the results to the values recommended by the Test of Infant Motor Performance (TIMP).

Method: Newborns between 34 and $41^{6 / 7}$ weeks of corrected gestational age, breathing spontaneously and presenting state of consciousness 4 or 5 , according to Brazelton, were included. TIMP was used to evaluate the motor performance. Results: The age groups of 34-35 and 36-37 weeks showed on average TIMP scores similar to the reference values ( $p>0.05$ ), while in the age groups of 38-39 weeks and 40-41 weeks TIMP scores were statistically lower than the reference values $(\mathrm{p}<0.001$ and $\mathrm{p}=0.018$, respectively). The $34-35$ and $36-37$ week groups were rated as average, while the 38-39 and 40-41 week groups were defined as low average. Classifications below average and very below average were not observed.

Conclusion: The newborns showed average scores compared to the TIMP reference values; however, there were two groups whose performances were within the low average. There was no significant difference in motor performance of newborns in the age groups of 38-39 and 40-41 weeks. This behavior suggests that the sample studied has special features that possibly negatively influenced their motor performance. The results showed that the TIMP is a very useful tool and can be used safely in tertiary neonatal units.

Keywords: newborn, motor performance, TIMP, premature, motor delay assessment.

\section{INTRODUCTION}

Monitoring of motor development in newborns discharged from the intensive care unit (ICU) is of great importance for early detection of possible deficits and to prevent and minimize consequences. The earlier the diagnosis of motor delay and therapeutic intervention, the less the future impact on child development. ${ }^{1-3}$ Knowledge of the sequence of development and use of standardized and validated assessment tools are useful to guide professionals on whether to refer newborns at risk to specialized services. ${ }^{4,5}$ The standardization of most motor development assessment scales was done in European countries and North America. There is little research on this topic in children in underdeveloped or developing countries. ${ }^{6}$
In Brazil, some authors have established the profile of acquisition of motor skills both in relation to the pattern and the pace at which they are processed, trying to set rules to assess normality. ${ }^{6,7,9}$ The Test of Infant Motor Performance (TIMP) is the only discriminative instrument of evaluation and prognosis developed for preterm infants with gestational age of 34 weeks to 4 months corrected gestational age ( $\mathrm{cGA}$ ) with high predictive value for use in the neonatal unit. This is a postural and selective motor control test whose purpose is to record longitudinally the motor performance of newborns at risk for delays in motor skills. ${ }^{10}$ In Brazil, although TIMP is widely used, research is needed to establish the behavior of high risk newborns in the intensive care unit. Newborns 
admitted to the Neonatal Center of Instituto da Criança, HC-FMUSP, constitute a population at high risk for delayed motor development due to prematurity and complications derived from maternal and/or neonatal illness. Therefore, due to the characteristics of these patients, motor impairment may be more frequent in this population. The hypothesis analyzed in this study is that there may be differences between the motor development of Brazilian newborns discharged from Neonatal Intensive Care Unit (NICU) and the normative values of the TIMP. The objective was to characterize the motor performance of newborns admitted to the NICU and compare them to TIMP reference values.

\section{Method}

We conducted a prospective cross-sectional study of 136 hospitalized newborns admitted to the Neonatal Center of Instituto da Criança, HC-FMUSP, who met the following criteria: corrected gestational age between 34 and 416/7 weeks; in common cradle; breathing spontaneously in room air; and presenting state of consciousness 4 or 5 , according to Brazelton. ${ }^{11}$ Neonates undergoing invasive or noninvasive mechanical ventilation for $\geq 96 \mathrm{~h}$, with congenital malformations, genetic syndromes, congenital infections, chronic lung disease, musculoskeletal disorders, intracranial hemorrhage grade II, III and IV, periventricular leukomalacia, neurological disorders, congenital heart disease, children born to users of illicit drugs, 5 minute Apgar < 7, exchange transfusion, or state of consciousness $1,2,3$ or 6 according to Brazelton were excluded. ${ }^{11}$

A database was created with prenatal, perinatal, and postnatal information. We used the TIMP (version 2.0, 2005) to assess motor performance. The test was administered by a trained physiotherapist, once in each newborn (NB), at the time that it met the study's inclusion criteria during hospitalization. To evaluate the behavioral state, we used the Brazelton scale for states of consciousness. ${ }^{11}$ To compare the infants studied with normative test values, they were divided into four groups according to the cGA: NB with cGA between 34 and $35^{6 / 7}$ weeks; NB with cGA between 36 and $37^{6 / 7}$ weeks; NB with cGA between 38 and $39^{6 / 7}$ weeks; NB with cGA between 40 and $41^{6 / 7}$ weeks. After obtaining the total test score, the normative table of the TIMP was applied. Newborns were classified as within the average, low average, below average or much below average. ${ }^{10}$

Parent/guardian authorization was obtained by signing a Free and Informed Consent form. The study was approved by the Ethics Committee for Analysis of Research Projects of the HC-FMUSP.

\section{ResULTS}

Regarding maternal characteristics according to age groups, and comparison between groups, the number of pregnancies was lower in mothers of newborns with 34-35 and 3637 weeks $(\mathrm{p}=0.014)$. Hypertension was more frequent among the mothers of newborns with 38-39 and 40-41 weeks $(\mathrm{p}=0.008)$, while gestational diabetes mellitus was more frequent among mothers in the group of 34-35 and 36-37 weeks $(\mathrm{p}=0.024)$. There was a higher frequency of infections among mothers of newborns with 38-39 weeks ( $\mathrm{p}=0.013$ ). There was no significant difference between the groups with respect to characteristics such as maternal age $(\mathrm{p}=0.808)$, heart disease $(\mathrm{p}=0.076)$, psychiatric disease $(\mathrm{p}=0.652)$, neurologic disease $(\mathrm{p}=0.268)$, cancer $(\mathrm{p}=0.842)$, use of prenatal corticosteroids $(\mathrm{p}=0.119)$, and smoking habit $(\mathrm{p}=0.119)$.

After characterizing the motor performance, we observed mean values of TIMP score of 46.6 for the group of 34-35 weeks, 53.1 for the group of 36-37 weeks, 49.8 for the group of 38-39 weeks, and 57.7 for the group of 40-41 weeks (Tables 1 and 2). According to the normative values of the TIMP, the groups of 34-35 and 36-37 weeks were classified as within the average, while the groups of 38-39 and 40-41 weeks were classified as low average. Classifications below average and well below the average were not obtained in any of the groups.

\section{Discussion}

We noted that, except for gender and type of delivery, all characteristics analyzed were different among the groups. This fact was expected, since these were newborns within different gestational age ranges. The lack of difference in relation to gender and type of delivery shows the homogeneity of the study population with respect to these variables. The use of oxygen for a longer time, the use of continuous positive airway pressure (CPAP) for a longer time, more prolonged hospitalizations, and increased frequency of respiratory conditions in infants with corrected gestational ages of 34-35 and 36-37 weeks reflect the severity of the clinical status of these patients. Due to the lower gestational age at birth, there was a need for more prolonged ventilatory support. The prevalence of cesarean sections in all groups is compatible with the level of complexity of the hospital, which admits referred pregnant women with various complications related to pregnancy. As for nutritional adequacy, there was a predominance of newborns appropriate for gestational age (AGA). Observed neurological disorders were uncommon, with grade I intraventricular hemorrhage in three newborns and agenesis of the septum pellucidum in another. All other newborns had normal findings on cranial ultrasonography (Table 1). 
TABLE 1 Characteristics of the newborns and comparison between groups.

Variable
Group

34-35 weeks

$(\mathrm{N}=37)$

GA at birth (weeks)

Mean (SD)

Median (P25; P75)

(Min.; max.)

Corrected GA (weeks)

Mean (SD)

Median (P25; P75)

(Min.; max.)

Birth weight (g)

Mean (SD)

Median (P25; P75)

(Min.; max.)

Weight at assessment $(\mathrm{g})$

Mean (SD)

Median (P25; P75)

(Min.; max.)

Time of MV (days)

Mean (SD)

Median (P25; P75)

(Min.; max.)

Time of CPAP (days)

Mean (SD)

Median (P25; P75)

(Min.; max.)

Time of $\mathrm{O}_{2}$ (days)

Mean (SD)

Median (P25; P75)

(Min.; max.)

Time of hospitalization

Mean (SD)

Median (P25; P75)

(Min.; max.)

Gender, n (\%)

Female

Male

Type of delivery, $\mathbf{n}$ (\%)

Vaginal

C-section

Forceps

Nutritional status, $\mathbf{n}(\%)$

SGA

AGA

BGA

$32.7(2)$

$32.7(2)$

$33(31.4 ; 34.1)$

$(28.1 ; 35.3)$

$34.9(0.6)$

$(34 ; 35.9)$

$1737.7(430.6)$

$(920 ; 2720)$

(1210; 2510)

$0.6(1.4)$

$0(0 ; 0.5)$

$(0 ; 6)$

$1.5(2.0)$

$0(0 ; 3)$

$(0 ; 7)$

$2.6(4.2)$

$1(0 ; 2)$

$(0 ; 21)$

$14.9(10.8)$

$12(7 ; 21)$

$(2 ; 45)$

$19(51.4)$

$18(48.6)$

$$
9(24.3)
$$

$28(75.7)$

$0(0.0)$

$10(27.0)$

$26(70.3)$

$1(2.7)$
$34.9(34.4 ; 35.3)$

$1680(1460 ; 2072.5)$

$1815.8(270.1)$

$1800(1622.5 ; 1997.5)$

36-37 weeks

$(\mathrm{N}=31)$

$(\mathrm{N}=38)$

$35.3(1.8)$
$35.6(34 ; 37)$
$(31.1 ; 37.7)$

$38.2(1.2)$

$38.4(38 ; 38.9)$

$(32.3 ; 39.4)$

$<0.001 *$

$38.9(0.6)$

$38.9(38.5 ; 39.3)$

$(38 ; 39.9)$

$(36 ; 37.9)$

(3);

$201.8(655.3)$

$1946.1(544.0)$

$1880(1480 ; 2400)$

(900; 3190)

$3100(2602.5 ; 3490)$

(1390; 3960)

2043.7 (384.0)

2888.4 (571.4)

2975 (2521.3; 3305)

(1645; 3790)

(1425; 2860)

$(1645,3790)$

$0.4(2.3)$

$0(0 ; 0)$

$(0 ; 14)$

$(0 ; 3)$

$0.2(0.6)$

$0(0 ; 0)$

$0.4(1.1)$

$0(0 ; 0)$

$(0 ; 5)$

$0.7(1.2)$

$0(0 ; 1)$

$(0 ; 5)$

$11.3(11.0)$

$8(3 ; 17)$

$(1 ; 45)$

$0.1(0.3)$

$0(0 ; 0)$

$(0 ; 2)$

$0.1(0.4)$

$0(0 ; 0)$

$(0 ; 2)$

;)

4.7 (6.7)

$3(2 ; 4)$

$(1 ; 42)$

16 (51.6)

$15(48.4)$

17 (44.7)

21 (55.3)

$4(12.9)$

24 (77.4)

3 (9.7)

11 (28.9)

27 (71.1)

$0(0.0)$

15 (48.4)

$16(51.6)$

$0(0.0)$
$6(15.8)$

$29(76.3)$

3 (7.9)
40-41 weeks

$(\mathrm{N}=30)$

$<0.001 *$

$39.5(1.4)$

$39.9(39.2 ; 40.3)$

(34.7; 41.1)

$$
40.5(0.5)
$$

$40.4(40.1 ; 40.7)$

(40; 41.6)

$3045.7(707.6)$

$3165(2720.3 ; 3602.5)$

$(1310 ; 4190)$

$<0.001 *$

$2957.8(545.6)$

3002.5 (2638.8; 3300)

$(1770 ; 4075)$

$<0.001 *$

$<0.001^{*}$

p 
TABLE 1 (Cont.) Characteristics of the newborns and comparison between groups.

\begin{tabular}{|c|c|c|c|c|c|}
\hline \multirow[t]{2}{*}{ Variable } & \multicolumn{4}{|l|}{ Group } & \multirow[t]{2}{*}{$\mathbf{P}$} \\
\hline & $\begin{array}{l}34-35 \text { weeks } \\
(N=37)\end{array}$ & $\begin{array}{l}36-37 \text { weeks } \\
(N=31)\end{array}$ & $\begin{array}{l}38-39 \text { weeks } \\
(N=38)\end{array}$ & $\begin{array}{l}40-41 \text { weeks } \\
(N=30)\end{array}$ & \\
\hline Respiratory disorders, n (\%) & & & & & $<0.001$ \\
\hline No & $12(32.4)$ & $23(74.2)$ & $36(94.7)$ & $25(83.3)$ & \\
\hline Yes & $25(67.6)$ & $8(25.8)$ & $2(5.3)$ & $5(16.7)$ & \\
\hline \multicolumn{6}{|l|}{ Neurological disorders, n (\%) } \\
\hline No & $33(89.2)$ & $30(96.8)$ & $38(100.0)$ & $30(100.0)$ & $0.034 \#$ \\
\hline Yes & $4(10.8)$ & $1(3.2)$ & $0(0.0)$ & $0(0.0)$ & \\
\hline TIMP score & & & & & $<0.001 *$ \\
\hline Mean (SD) & $46.6(9.6)$ & $53.1(8.1)$ & $49.8(8.8)$ & $57.7(8.3)$ & \\
\hline Median (P25; P75) & $45(39.5 ; 55)$ & $54(48 ; 60)$ & $50(43 ; 57)$ & $58.5(54.8 ; 62)$ & \\
\hline (Min.; max.) & $(31 ; 64)$ & $(30 ; 67)$ & $(27 ; 68)$ & $(34 ; 74)$ & \\
\hline
\end{tabular}

Chi-squared test; \#Likelihood ratio test; *ANOVA; **Kruskal-Wallis.

GA: gestational age; SD: standard deviation; MV: mechanical ventilation; CPAP: continuous positive airway pressure; SGA: small for gestational age; AGA: appropriate for gestational age; BGA: big for gestational age.

TABLE 2 Multiple comparisons of TIMP scores among the age groups.

\begin{tabular}{lllllll} 
Groups compared & Mean difference & Standard error & $\mathbf{P}$ & & $\mathbf{9 5 C I}$ \\
\cline { 3 - 7 } & & & Inferior & Superior \\
\hline 34-35 weeks versus 36-37 weeks & -6.48 & 2.14 & $\mathbf{0 . 0 1 8}$ & -12.20 & -0.75 \\
\hline 34-35 weeks versus 38-39 weeks & -3.14 & 2.03 & 0.744 & -8.58 & 2.29 \\
\hline 34-35 weeks versus 40-41 weeks & -11.08 & 2.16 & $<\mathbf{0 . 0 0 1}$ & -16.86 & -5.30 \\
\hline 36-37 weeks versus 38-39 weeks & 3.33 & 2.13 & 0.716 & -2.36 & 9.03 \\
\hline 36-37 weeks versus 40-41 weeks & -4.60 & 2.25 & 0.256 & -10.63 & 1.42 \\
\hline 38-39 weeks versus 40-41 weeks & -7.64 & 2.15 & $\mathbf{0 . 0 0 2}$ & -13.68 & -2.19 \\
\hline
\end{tabular}

Bonferroni's multiple comparisons.

On the characterization of motor performance, all newborns presented normal TIMP results, i.e., classifications below average and well below average were not observed. However, groups with corrected gestational age of 38-39 and 40-41 weeks presented scores in the low average range. The absence of newborns outside the normal range on the TIMP scale may be related to the sample selection criteria, which did not include patients with neurological morbidities. Studies that include infants with neonatal intraventricular hemorrhage and seizures show that these risk factors are worse performance determinants based on TIMP. ${ }^{12}$ Lee et al. ${ }^{13}$ correlated risk factors and TIMP in 80 newborns admitted to intensive care unit at the age of 40 weeks. Birth weight, multiple births, gender, type of delivery, Apgar, seizures, and intraventricular hemorrhage were analyzed. The authors found that intraventricular hemorrhage was the risk factor most strongly correlated with low TIMP scores. Other factors cited were C-section, seizures, multiple births and low birth weight.

Raniero et al. ${ }^{7}$ characterized the pattern and race of acquisition of motor skills of preterm infants in the first 4 months of corrected age, comparing them to a group of term infants. The newborns were evaluated monthly, from 0 to 4 months of age based on TIMP. Preterm infants had mean scores higher than those presented by term infants between 1 to 4 months old. In this group, the rate of motor acquisition was higher between 0 and 1 month than between 3 to 4 months. The authors concluded that preterm infants have a motor development pattern similar to the typical regarding the sequence of acquired skills and accelerated pace from birth to one month of age. Similar results were observed in our study, where the younger infants, groups of 34-35 and 36-37 weeks, had better scores than older infants, between 38-39 and 40-41 weeks, compared to the reference values of TIMP (Chart 1). 


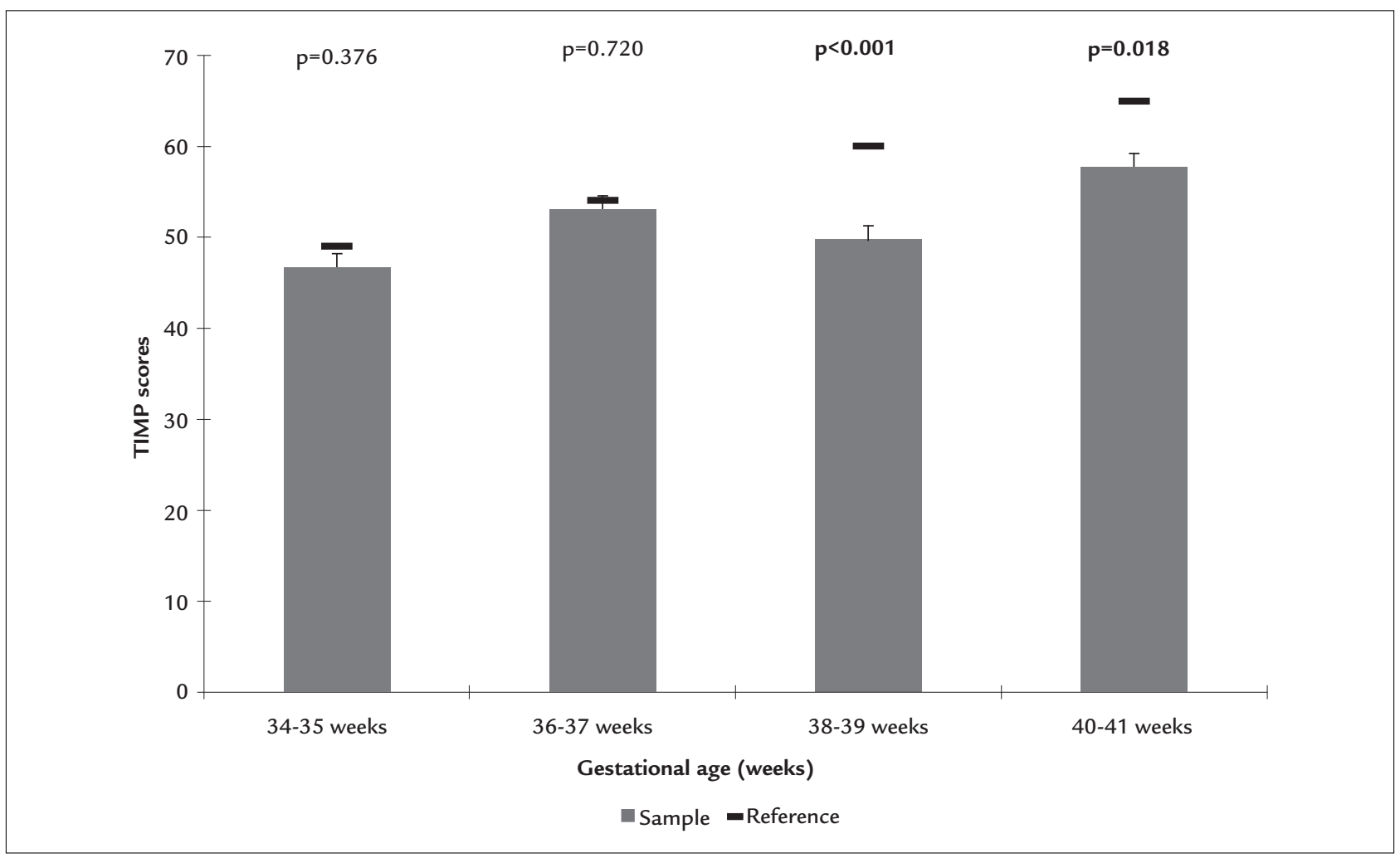

CHART 1 Mean values of TIMP scores according to age groups and the results of the comparative tests.

Campbell et al..$^{14}$ evaluated the discrimination ability of the TIMP scale among children with different degrees of risk for delayed motor development, based on morbidity and perinatal medical complications. Ninety-eight children were evaluated until 4 months of age, divided into five groups: infants born at term or preterm without significant medical problems (low and intermediate risk, respectively), gestational age less than 30 weeks or birth weight $<1500 \mathrm{~g}$ (high risk), chronic pulmonary disease (high risk), and brain changes (high risk). Groups at low and medium risk did not differ, but showed significantly better performance than the high-risk group. Children with brain disorders had a significantly lower performance than the others. The authors found that TIMP can discriminate against children with different risks for motor delay.

Preterm newborns with gestational age below 30 weeks and birth weight less than $1500 \mathrm{~g}$ constitute a population at high risk of showing deficits in neurodevelopment in case of clinical complications..$^{18}$ In our study, most newborns had mean gestational age at birth greater than 32 weeks and birth weight greater than $1500 \mathrm{~g}$; in addition, they did not have intracranial hemorrhage, chronic lung disease or convulsive syndrome. Therefore, the absence of these biological risk factors certainly contributed to the motor performance within the average. Guimarães et al. ${ }^{15}$ reported different results after comparing preterm newborns with corrected gestational age of 38-40 weeks and term newborns based on TIMP. Among 46 preterm newborns with gestational age at birth between 28 and 33 weeks, $26.1 \%$ were classified as atypical, with significantly lower average score, while $100 \%$ of the term newborns were typical. Even though the higher frequency of developmental disorders occurs in children with a history of prematurity and low birth weight, there is controversy as to the characteristics of these sequelae and their long-term progression. ${ }^{16}$ Comparative studies with preterm and term newborns demonstrated that there are differences in motor performance between them, and also among the preterm themselves, depending on their clinical status and gestational age. ${ }^{15,17}$ Van Haastert et al., ${ }^{18}$ after evaluating 800 preterm newborns with 1 to 18 months of corrected age assessed based on the Alberta Infant Motor Scale, observed that they showed a different evolution of gross motor development compared to term newborns, suggesting that the scales should be adapted according to gestational age at birth.

Several factors may contribute to the difficulties of accurate assessment of motor development, such as the 
small number of specific diagnostic tools, the transience of neuromotor disorders in preterm infants in early life and the effects of environmental factors. ${ }^{19}$ In Brazil, some studies ${ }^{4,5,20,21}$ sought to establish the developmental profile of normal infants; however, there are few longitudinal studies with representative samples to characterize the preterm newborn profile. Such knowledge could facilitate the differentiation between preterm newborns with actual motor deficits and those whose pace of acquisition is slower, but does not lead to future motor impairment. Investigations ${ }^{8,22,23}$ on normal infants in order to determine the profile of motor skill acquisition, regarding both pattern and pace of development, reported differences in the pattern of motor development between children from different countries. These differences occurred in children belonging to different cultural groups and also within the same cultural group, confirming that the neuropsychomotor development (NPMD) depends on biological, cultural and environmental risk factors.

Campbell et al..$^{24}$ studied 990 children at risk for developmental delay in 11 regions of the United States. They analyzed the TIMP scores in relation to sex, risk of poor performance, race, and ethnicity. They noted that Hispanic children had significantly lower scores than children in all other ethnic groups. There was no difference in relation to sex. In our study, a statistically significant difference was found in TIMP score compared to normative values only in the 38-39 and 40-41 week groups (Chart 1), and it was not able to say that Hispanic ethnicity influenced the results observed in these two groups. Analyzing the behavior of all groups compared to each other, we observed that the mean TIMP scores of the group with corrected age of 36-37 weeks was significantly higher than those observed in the 34-35 week group ( $p=0.018$ ). Similarly, the group with 40-41 weeks showed a mean score higher than that observed in the 34-35 and 38-39 week groups (Chart 1).

In the normative table of the TIMP scale, there is a progressive score increase as the corrected age increases, i.e., the greater the maturity of the central nervous system, the more the motor abilities will be developed and observed when the test is performed. To check this progression and the changes in TIMP scores over time, Rose et al. ${ }^{25}$ evaluated 25 children with biological risk of developmental delay, born with gestational age less than or equal to 30 weeks, at 32 weeks of post-conceptual gestational age, and at 36 weeks. There was a significant increase in TIMP scores over time, but no correlation between risk variables. In our study, this increase was progressive up to the corrected gestational age of 36 weeks. In the 38-39 week group, however, there was a significant decrease in TIMP score. The group of 40-41 weeks, despite showing a rebound in the progression curve, maintained a significant difference compared to the normative value (Chart 1). This behavior suggests that the two groups with lower scores may have presented characteristics that adversely affected their motor performance. We find it important to analyze the maternal factors, as the hospital of high complexity where the study was conducted primarily receives high-risk pregnant women with chronic diseases such as hypertension, diabetes, heart disease, and more. We found the groups that achieved lower mean TIMP scores had the highest frequency of maternal infection, diabetes mellitus, and smoking habit. It is known that infections during pregnancy are associated with a higher rate of prematurity, and that chorioamnionitis and urinary infection, complications frequently observed in Brazil, increase the risk of neonatal morbidity. ${ }^{26}$ Likewise, newborns to diabetic mothers have increased risk of prematurity, metabolic disorders and malformations. Despite the developments in obstetric and neonatal care, diabetes remains a major complication in pregnancy. ${ }^{27}$ Pre- and perinatal exposure to nicotine is related to changes in cognition and development. Smoking during pregnancy accounts for $20 \%$ of fetuses with low birth weight and $8 \%$ of premature births, and may contribute to significant changes in the development of the central nervous system. ${ }^{28}$ While the use of illicit drugs was considered one of the exclusion criteria, maternal smoking was accepted in the selection of our patients. Even though there was no statistical association, this factor was present in 39\% of the newborns in the 38-39 week group, which obtained a low mean score.

So far, the prognosis of motor development of infants born to mothers with serious illnesses during pregnancy is a major challenge for health professionals. Santos et al., ${ }^{29}$ in a meta-analysis of 17 articles selected from 455 studies, critically reviewed the evaluation instruments most widely used today for early screening and identification of abnormalities in child development. They highlighted the importance of the TIMP scale among the instruments studied due to its high sensitivity and specificity in young children.

\section{Conclusion}

The TIMP is a very useful tool and can be used safely in tertiary neonatal units. The performance ranked within the low mean range in two groups of newborns discharged 
from an intensive care unit indicates the need for careful monitoring of these children in order to detect early possible future deficits.

We recommend that the evaluation of neonates and infants based on TIMP score be part of the preparation of your treatment plan during hospitalization. Early evaluation can also be of great value to establish the future potential of these children, and follow-up after hospital discharge.

\section{Resumo}

Caracterização do desempenho motor de recém-nascidos em unidade neonatal de nível terciário

Objetivo: caracterizar o desempenho motor de recém-nascidos em unidade neonatal de nível terciário e comparar os resultados com os valores normativos preconizados pelo Test of Infant Motor Performance (TIMP).

Método: foram incluídos recém-nascidos entre 34 e 41 6/7 semanas de idade gestacional corrigida, em respiração espontânea e estado de consciência 4 ou 5, segundo Brazelton. Para avaliar o desempenho motor, foi utilizado o TIMP.

Resultados: os grupos etários de 34-35 e 36-37 semanas apresentaram em média escore TIMP semelhante aos valores de referência; já nos grupos etários 38-39 semanas e 40-41 semanas, os escores TIMP foram estatisticamente menores que os valores de referência ( $\mathrm{p}<0,001$ e $\mathrm{p}=0,018$, respectivamente). Os grupos de 34-35 e 36-37 semanas foram classificados como dentro da média, enquanto os grupos 38-39 e 40-41 semanas como média baixa. As classificações abaixo da média e muito abaixo da média não foram observadas.

Conclusão: os recém-nascidos apresentaram escores dentro da média quando comparados aos valores de referência do TIMP; porém, houve dois grupos cujo desempenho se situou na classificação média baixa. Houve diferença significativa no desempenho motor dos recém-nascidos nos grupos etários de 38-39 e 40-41 semanas. Esse comportamento sugere que a casuística estudada apresenta particularidades que, possivelmente, influenciaram de modo negativo o desempenho motor. Os resultados obtidos mostram que o TIMP é instrumento de grande utilidade e pode ser usado com segurança em unidade neonatal terciária.

Palavras-chave: recém-nascido, desempenho motor, TIMP, prematuro, avaliação de atraso motor.

\section{References}

1. Araújo ATC, Eickmann, SH, Coutinho SB. Factors associated with late motor development in premature children admitted to a neonatology unit. Rev Bras Saúde Matern Infant. 2013; 13(2):119-28.

2. Mancini MC, Megale L, Brandão MB, Melo APP, Sampaio RF. Efeito moderador do risco social na relação entre risco biológico e desempenho funcional infantil. Rev Bras Saúde Matern Infant. 2004; 4(1):25-34.

3. Silva NDSH, Lamy Filho FL, Gama MEA, Lamy ZC, Pinheiro AL, Silva DN. Instrumentos de avaliação do desenvolvimento infantil de recém-nascidos prematuros. Rev Bras Cresc Desenv Hum. 2011; 21(1):85-98.

4. Barbosa VC, Formiga CKMR, Linhares MBM. Avaliação das variáveis clínicas e neurocomportamentais de recém-nascidos pré-termo. Rev Bras Fisioter. 2007; 11(4):275-81.

5. Eickmann SH, Lira PIC, Lima MC. Desenvolvimento mental e motor aos 24 meses de crianças nascidas a termo com baixo peso. Arq Neuropsiquiatr. 2002; 60(3B):748-54.

6. Mancini MC, Teixeira S, Araújo LG, Paixão ML, Magalhães LC, Coelho ZAC, et al. Estudo do desenvolvimento da função motora aos 8 e 12 meses de idade em crianças nascidas pré-termo e a termo. Arq Neuropsiquiatr. 2002; 60(4):974-80

7. Raniero EP, Tudella E, Mattos RS. Padrão e ritmo de aquisição das habilidades motoras de lactentes pré-termo nos quatro primeiros meses de idade corrigida. Rev Bras Fisioter. 2010; 14(5):396-403.

8. Grantham-Mcgregor SM, Lira PIC, Ashworth A, Morris SS, Assunção MAS The development of low birth term infants and the effects of the environment in Northeast Brazil. J Pediatr. 1998; 132(4):661-6.

9. Santos RS, Araújo APQC, Porto MAS. Diagnóstico precoce de anormalidades no desenvolvimento em prematuros: instrumentos de avaliação. J Pediatr (Rio J). 2008; 84(4):289-99.

10. Campell SK. The Test of Infant Motor Peformance. Test User's Manual Version 2.0. Chicago: Infant Motor Performance Scales; 2005.

11. Brazelton TB. Neonatal behavioral assessment scale. 2.ed. Philadelphia: JB Lippincott; 1984. (Clinics in Developmental Medicine 88).

12. Tekgul H, Gauvreau K, Soul J, Robertson R, Stewart J, Volpe J, et al. The current etiological profile and neurodevelopmental outcome of seizures in term newborn infants. Pediatrics. 2006; 117(4):1270-80.

13. Lee EJ, Han JT, Lee JH. Risk factors affecting Test of Infant Motor Performance (TIMP) in pre-term infants at post-conceptional age of 40 weeks. Dev Neurorehabil. 2012; 15(2):79-83.

14. Campbell SK, Hedeker D. Validity of the Test of Infant Motor Performance discriminating among infants with varying risk for poor motor outcome. J Pediatr. 2001; 139(4):546-51.

15. Guimarães CLN, Reinaux CM, Botelho ACG, Lima GMS, Cabral Filho JE. Desenvolvimento motor avaliado pelo Test of Infant Motor Performance: comparação entre pré-termo e a termo. Rev Bras Fisioter. 2011; 15(5):357-62.

16. Oliveira GE, Magalhães LC, Salmela LFT. Relação entre muito baixo peso ao nascimento, fatores ambientais e o desenvolvimento motor e cognitivo de crianças aos 5 e 6 anos. Rev Bras Fisioter. 2011; 15(2):138-45.

17. Goyen TA, Lui K. Longitudinal motor development of apparently normal high-risk infants at 18 months, 3 and 5 years. Early Hum Dev. 2002; 70(12):103-15.

18. Van Haastert IC, de Vries LS, Helders PJ, Jongmans MJ. Early gross motor development of preterm infants according to the Alberta Motor Scale. J Pediatr. 2006; 149(5):617-22.

19. Kolobe T HA, Bulanda M, Susman L. Predicting motor outcome at preschool age for infants tested at 7,30, 60 e 90 days after term age using The Test Of Infant Motor Performance. Phys Ther. 2004; 84(12):1144-56.

20. Morris SS, Victoria CG, Barros FC, Halpern R, Menezes AMB, Cesar JA, et al. Lenght and ponderal index at birth: associations with mortality, hospilizations, development and post natal growth in Brazilians Infant. Int J Epidemiol. 1998; 27(2):242-7.

21. Santos DCC, Gabbard C, Gonçalves VMG. Motor development during the first 6 months: the case of Brazilian infants. Infant Child Dev. 2000; 9(3):161-6.

22. Brill B. Motor development and cultural attitudes. Themes in Motor Development. 1986; 35:297-313.

23. Capute AJ, Shapiro BK, Palmer FB, Ross A, Watchtel RC. Normal gross motor development: the influences of race, sex and socio-economic status. Dev Med Child Neurol. 1985; 27(5):635-43. 
24. Campbel SK, Levy P, Zawacki L, Liao PJ. Population-based age standards for interpreting results on the test of motor infant performance. Pediatr Phys Ther. 2006; 18(2):119-25.

25. Rose RU, Westcott SL. Responsiveness of the Test of Infant Motor Performance (TIMP) in infants born preterm. Pediatr Phys Ther. 2005; 17(3):219-24.

26. Bittar RE, Zugaib M. Indicadores de risco para o parto prematuro. Rev Bras Ginecol Obstet. 2009; 31(4):203-9.
27. HAPO Study Cooperative Research Group, Metzger BE, Lowe LP, Dyer AR, Trimble ER, Chaovarindr U, Coustan DR, et al. Hyperglycemia and adverse pregnancy outcomes. N Engl J Med. 2008; 385(19):1991-2002.

28. Leopércio W, Gigliotti A. Tabagismo e suas peculiaridades durante a gestação: uma revisão crítica. J Bras Pneumol. 2004; 30(2):176-85.

29. Santos RS, Araújo APQC, Porto MAS. Diagnóstico precoce de anormalidades no desenvolvimento em prematuros: instrumentos de avaliação. J Pediatr (Rio J). 2008; 84(4):289-9. 